\title{
A social work study on effectiveness of transactional analysis training on social adjustment: A case study of women with spouses with drug addiction
}

\author{
Seyedeh Maryam Emam Jomeh Zadeh ${ }^{\mathrm{a}^{*}}$, Yousef Gorji ${ }^{\mathrm{b}}$ and Afsaneh Javadzadeh
}

${ }^{a}$ MS Student, Counseling Department, Islamic Azad University of Khomeinishahr, Khomeinishahr Branch, Daneshjou Blvd, Iran

${ }^{b}$ Assistant Professor, Counseling Department, Islamic Azad University of Khomeinishahr, Khomeinishahr Branch, Daneshjou Blvd, Iran ${ }^{c}$ Counseling Department, Islamic Azad University of Khomeinishahr, Khomeinishahr Branch, Daneshjou Blvd, Iran

\section{H R O N I C L E A B S T R A C T}

Article history:

Received October 14, 2012

Received in revised format

24 November 2012

Accepted 30 December 2012

Available online

January 52013

Keywords:

Transactional analysis

Addicted people

Esfahan

\begin{abstract}
In this study, we investigate whether transactional analysis (TA) training could improve social adjustment in a case study of women with spouses with drug addiction. This experimental study was performed on 40 people who were addicted to drugs and were under medication in some clinical centers in city of Esfahan, Iran. The patients were randomly divided into two groups (control and an experimental group). The experimental group was trained under transactional training for 8 one-hour sessions. Cronbach alpha was calculated as 0.89 , which is well above the minimum acceptable. The results of the survey show that the means of two groups before test are close to each other. However, after TA has been accomplished, there is meaningful difference between these two groups. The result of F-value statistical test is also meaningful when the level of significance is five percent. In other word, there are some evidences to believe that transactional analysis training impacts on our surveyed people, positively.
\end{abstract}

\section{Introduction}

World Health Organization (WHO) considers drug problem in different forms of generation, transmission, distribution and consumption in the world as important as the other three problems of mass destruction weapons, environment pollution, poverty and social gap. In fact, drug addiction is one of the most important human disasters in all over the world, which damages human life. Drug addiction creates different social and economic disorders in any society, which jeopardizes the structure of families. Drug addiction has been an issue for many decades and there is no immediate solution to remove it from society over a night. The family plays essential role in shaping human civilization and strengthening families and relationships could lead to better mental health for family formation (Schiraldi, 2001). Drugs influence in many important issues such as accidents, violence, criminal behavior and family conflicts. Obviously, we could expect that such problem could easily

*Corresponding author. Tel: +989133036951

E-mail addresses: M.emam jomeh zadeh @ iaukhsh.ac.ir (M.Emam jomeh zadeh) 
influence people's spouses. These negative effects can include damage to the physical, psychological, social or individual job performance and ultimately impacts negatively on mood and behavior. This relationship is unhealthy and not only shaken the foundations of the family, but also it can create social adjustment problems. In fact, compatibility with the environment is a skill that must be learned and through this process, the person tries to fight with confronting stress, tensions and conflicts.

Transactional Analysis (TA) is a technique developed originally by Eric Berne (Berne, 1964) as a simplified technique to psychotherapy. Wachtel (1980) demonstrated TA applications for different activities within travel and tourism organizations including supervising personnel, developing better relationships with customers, and improvement of interpersonal communication and feelings. The study analyzed process of TA training in tourism/hospitality enterprises. Jansma and French (1979) stated TA as an alternative approach for managing inappropriate behavior. However, George and Gowell (1973) explained that sensitivity groups, encounter groups, and T groups could be severely criticized, strongly supported, greatly feared, misunderstood, misused, and ultimately used in a different settings. They performed an empirical investigation and discussed that sensitivity training could beneficial to people preparing themselves for the health care fields. They showed that group experiences could help them in these areas and TA could be a valuable technique for enabling nursing students to detect their own feelings and the impact their feelings could have on others. They gave students a method they could use in settings other than academic, and in both personal and professional encounters.

McKimm and Forrest (2010) used TA to improve clinical and educational supervision and explained that the supervisor-trainee relationship could play an important role in ensuring the best continuing education for all trainees. One of the primary skills of supervision is to communicate effectively, which is sometimes a tedious task. They explored how two TA models, the Drama and Winner's triangles, could help supervisors work and communicate more effectively with trainees. Their models could be implemented to demonstrate these situations and what exactly is happening to the communication. The models provided techniques for breaking free from these frustrating encounters and moving towards the relationship with trainee. The models could also help understand the ways in which we are easily be pulled into games and offer insight into our own behaviours, not only with trainees, but also with patients, carers and colleagues. Fathipouri et al. (2010) investigated the effectiveness of transactional analysis training on the parent's function of high school boy students in

Rafsanjan in 2009. The results of the study indicated that the mean of the functional scores of posttest in the experimental group compared with the control group was statistically significant and concluded that TA training could be an effective method for an adult relationship and improve the weak relationships. Ohlsson (2002) investogated the effects of transactional analysis psychotherapy in therapeutic community treatment of drug addicts. Thunnissen et al. (2002) presented some experiences of patients after short-term inpatient transactional analysis psychotherapy. Chen et al. (2006) performed an assessment of cognitive-behavioral group therapy on patient depression and self-esteem.

In this study, we investigate whether a good TA training could improve social adjustment in a case study of women with spouses with drug addiction. The organization of this survey first presents details of the survey in section 2 while section 3 presents the results of our survey and the paper ends with concluding remarks.

\section{The proposed study}

This experimental study was performed on 40 people who were addicted to drugs and were under medication in some clinical centers in city of Esfahan, Iran. The patients were randomly divided into two groups (control and an experimental group). The experimental group was trained under transactional training for 8 one-hour sessions. Fig. 1 and Fig. 2 show patients' age and years of educations while Fig. 3 demonstrates their wives’ educational backgrounds. 


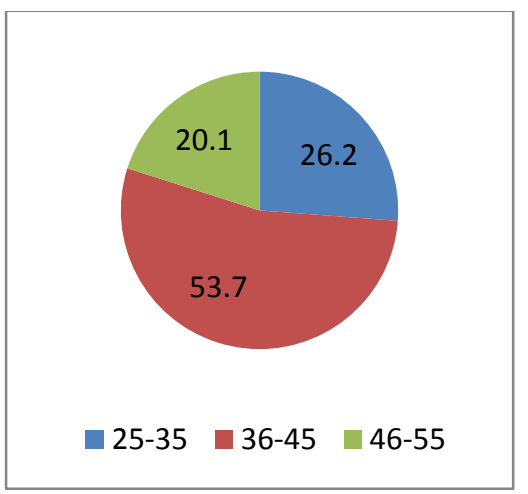

Fig. 1. Patients' age

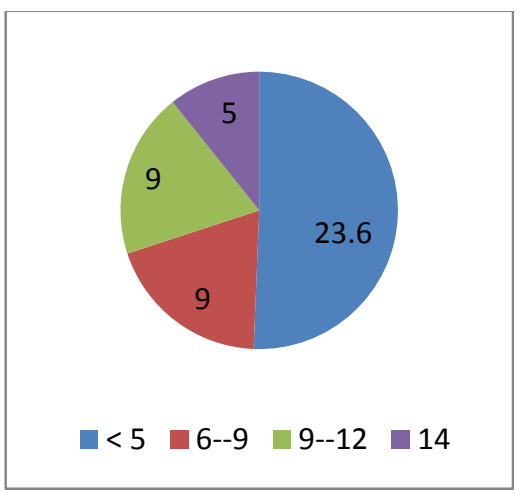

Fig. 2. Patients' years of educations

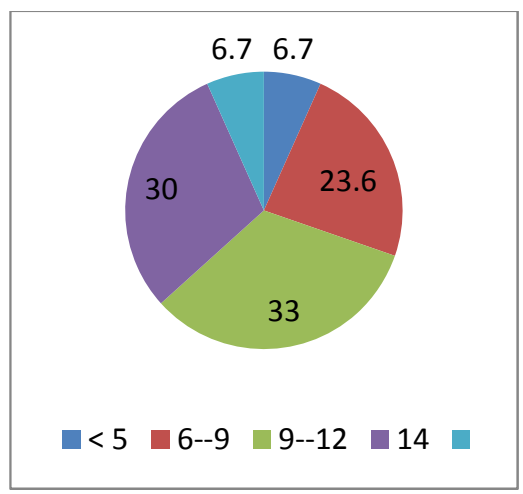

Fig. 3. Patients' wives' educational backgrounds

Cronbach alpha (Cronbach, 1951) was calculated as 0.89, which is well above the minimum acceptable limit of the survey and we can conclude that the questionnaire of the survey is good enough to test the hypothesis.

\section{The results}

In this section, we present details of our findings on the effect of TA program on two groups of addicted people. Table 1 shows the mean score of our investigation.

\section{Table 1}

The results of mean and standard deviation for control and experiment

\begin{tabular}{llll}
\hline Group & Stage & Mean & Standard deviation \\
\hline Control & Pre-test & 74.34 & 35.58 \\
& Post-test & 76.42 & 39.66 \\
\hline \multirow{2}{*}{ Experiment } & Pre-test & 72.93 & 32.51 \\
& Post-test & 129.42 & 31.17 \\
\hline
\end{tabular}

As we can observe from the results of Table 1, the means of two groups before test are close to each other. However, after TA has been accomplished, there is meaningful difference between these two groups. Table 2 shows the results of statistical tests.

Table 2

The results of analysis of variance

\begin{tabular}{lccccccc}
\hline Dependent variable & Sum of squares & df & Mean of squares & F & Sig. & $\begin{array}{c}\text { Effect } \\
\text { ratio }\end{array}$ & $\begin{array}{c}\text { Statistical } \\
\text { power }\end{array}$ \\
\hline Pre-test & 8567.84 & 1 & 8567.84 & 322.34 & 0.001 & 0.86 & 0.96 \\
Group & 3879.23 & 1 & 3879.23 & 159.52 & 0.03 & 0.31 & 0.82 \\
Error & 2462.63 & 28 & 573.32 & & & & \\
Total & 86642.21 & 30 & & & & & \\
\hline
\end{tabular}

As we can observe from the results of Table 2, F-value is statistically meaningful when the level of significance is five percent. In other word, we can conclude that transactional analysis training had positive impact on our group. 


\section{Conclusion}

We have investigated whether a good transactional analysis training could improve social adjustment in a case study of women with spouses with drug addiction. This experimental study was performed on 40 people who were addicted to drugs and were under medication in some clinical centers in city of Esfahan, Iran. The result of the survey has indicated that the means of two groups before test were close to each other. However, after TA was performed, there was meaningful difference between these two groups. The result of F-value statistical test is meaningful when the level of significance was five percent. In other word, we have concluded that transactional analysis training had positive impact on our group.

\section{Acknowledgment}

The authors would like to thank the anonymous referees for constructive comments on earlier version of this paper.

\section{References}

Berne, E. (1964). Games People Play. New York: Grove Press. ISBN 0-14-002768-8.

Chen, T. H., Lu, R. B., Chang, A. J., Chu, D. M., \& Chou, K. R. (2006). The evaluation of Cognitivebehavioral group therapy on patient depression and self-esteem. Archives of Psychiatric Nursing, 20(1), 3-11.

Cronbach, L. J. (1951). Coefficient alpha and the internal structure of tests. Psychometrika, 16(3), 297-334.

Fathipouri, M., Ebrahimi Nejad, G., Khosravi, S., Rezaeian, M., Pourshanazari, A. (2010). The effect of transactional analysis training on improving the parent's functions of high school boy students in Rafsanjan. Journal of Rafsenjan University of Medical Sciences, 9 (1), 47-58

George, J. A., \& Gowell, E. C. (1973). Transactional analysis in sensitivity groups for students of nursing. Nursing Forum, 12(1), 82-95.

Jansma, P., \& French, R. (1979). Transactional analysis: An alternative approach to managing inappropriate behavior. American Corrective Therapy Journal, 33(5), 155-162.

McKimm, J., \& Forrest, K. (2010). Using transactional analysis to improve clinical and educational supervision: The drama and winner's triangles. Postgraduate Medical Journal, 86(1015), 261-265.

Ohlsson, T. (2002). Effects of transactional analysis psychotherapy in therapeutic community treatment of drug addicts. Transactional Analysis Journal, 32(3), 153-177.

Schiraldi, G. (2001). The Self- Esteem Workbook: New Harbringer Press.

Thunnissen, M., Duivenvoorden, H. J., \& Trijsburg, R. W. (2002). Experiences of patients after shortterm inpatient transactional analysis psychotherapy. Transactional Analysis Journal, 31(2), 122128.

Wachtel, J. M. (1980). Transactional analysis training for the travel industry. Annals of Tourism Research, 7(3), 455-471. 